\title{
La recepción de la soteriología agustiniana en la corte de Teodorico
}

\author{
The reception of Augustinian soteriology at the court of Theodoric
}

Q Estefanía Sottocorno

Universidad de Buenos Aires - Universidad Nacional de Tres de Febrero, Argentina

Fecha de recepción: octubre 2018. Fecha de aceptación: noviembre 2018.

\begin{abstract}
Resumen
La sanción del concilio de Orange de 529, impulsada por Cesáreo de Arles y avalada por Bonifacio II, luego de un complicado traspaso en Roma, con la muerte de Félix IV y la disputa por la herencia papal entre godos y bizantinos, cristaliza las derivas dogmáticas que se venían desarrollando desde los febriles cuestionamientos a la autoridad del obispo de Hipona, irradiados especialmente a partir de los centros de disciplina monástica instalados en el sur de Galia, i. e., Marsella y Lérins, y el norte de África. En este marco, parece interesante observar el alcance de la influencia agustiniana, varias décadas después de la muerte del propio Agustín, sobre la producción literaria de los miembros más conspicuos de la intelligentsia romana al servicio de la corte ostrogoda.
\end{abstract}

\begin{abstract}
The sanction of the council of Orange of 529, impelled by Caesarius of Arles and endorsed by Bonifacius II, after a complicated succession in Rome, with the death of Felix IV and the dispute for the papal inheritance between Goths and Byzantines, crystallizes the dogmatic drifts that had been developing from the feverish questions to the authority of the bishop of Hippo, irradiated especially from the centers of monastic discipline installed in southern Gaul, i. e., Marseille and Lérins, and North Africa. In this frame, it seems interesting to observe the reach of the Augustinian influence, several decades after his own death, on the literary production of the most conspicuous members of the Roman intelligentsia at the service of the Ostrogothic court.
\end{abstract}

\section{Introducción}

El segundo concilio de Orange, celebrado el año 529, sanciona la posición agustiniana en el encendido debate sobre el rol de la gracia, que se había desarrollado a lo largo del siglo 
1. Hemos expuesto más ampliamente estos temas en diversos artículos, v. "Genadio de Marsella en la tradición de los De viris illustribus. Repercusiones de los debates soteriológicos en la historia de su transmisión", en: Anales de Historia Antigua, Medieval y Moderna 48 (2014: 47-78).

2. Agustín escribe los libros Sobre la gracia y el libro albedrí, Sobre la corrección y la gracia, Sobre la predestinación de los santos y Sobre el don de la perseverancia en este contexto. V. Trapé (1990). precedente. Tal posición reivindicaba la absoluta primacía del auxilio divino en la inclinación humana hacia el bien, así como la absoluta necesidad del mismo para la concreción de toda buena intención a lo largo de la vida de los hombres. Al calor de los debates que surgieron de la resistencia a tales ideas, emergió la tesis agustiniana más controvertida, aquella relacionada con la predestinación y con el margen de acción que quedaba entonces disponible para el libre albedrío. ${ }^{1} \mathrm{Si}$ bien Agustín insiste en que la misericordia atenúa la justicia divina, debe hacer frente explícitamente a la ríspida cuestión del destino de quienes no serán salvados, poniendo en juego el recurso de la presciencia: "Mas puede ser también acerca de aquellas cosas que Dios no hace, como es el pecado, de cualquier especie que sea" (Sobre la predestinación de los santos X, 19). Así afirma que si la misericordia divina habilita a la salvación de algunos, entre un conjunto que merece in toto la condena como consecuencia del pecado original, Dios no puede ser responsable por el mal que se ha colado en su creación, amén del conocimiento que tenga del mismo: "Gratuitamente, por tanto, han conseguido la elección los que la han conseguido, no precediendo ningún mérito de ellos, de suerte que dieran antes alguna cosa por la que les fuese retribuida; gratuitamente los hizo salvos" (VI, 11). Precisamente, este conocimiento constituye una presciencia porque Dios es el Ser pleno y necesario, autor de todo lo que existe, aun del tiempo. En tal sentido, es un Ser ajeno al tiempo, antes bien su dimensión es la eternidad, que no registra cambios, movimientos ni sucesiones, sino que implica la visión sinóptica de lo que nosotros percibimos en coordenadas temporales: crear es hacerlo -y querer hacerlo- eternamente, aunque el ser creado se despliegue luego con una lógica interna temporal, producto de su propio ser contingente.

Para esa fecha, hacía ya unos ocho años que Ennodio de Pavía había muerto, seis que Boecio había sido ejecutado -tras un confinamiento filosóficamente fecundo- y que Casiodoro -su gentil y pulido correspondiente, según dejan ver las Variae- lo había sucedido en el cargo de magister officiorum, y tres que Teodorico había partido dejando un grave problema de sucesión, para la delicada gestión de la Italia ostrogoda. Con todo, la sanción de 529, pergeñada por Cesáreo de Arles y avalada por Bonifacio II, luego de un complicado traspaso en Roma, con la muerte de Félix IV y la disputa por la herencia papal entre godos y bizantinos, cristaliza las derivas dogmáticas que se venían desarrollando desde los febriles cuestionamientos a la autoridad del obispo de Hipona, irradiados especialmente a partir de los centros de disciplina monástica instalados en el sur de Galia, i. e., Marsella y Lérins, y el norte de África. ${ }^{2}$ En este marco, parece interesante observar el alcance de la influencia agustiniana, varias décadas después de la muerte del propio Agustín, sobre la producción literaria de los miembros más conspicuos de la intelligentsia romana al servicio de la corte ostrogoda.

\section{Cesáreo y Ennodio en la corte ostrogoda}

Recordemos, en principio, que hacia el año 513 Cesáreo acudió precisamente a Ravena, bajo sospecha de traición al control ostrogodo recientemente instalado en el área de Arles (Klingshirn, 1994). En tal ocasión, en cambio, parece haber despertado la reverencia de Teodorico ante su misma santidad, al punto de inducirlo a brindar apoyo económico a los dictados de la caridad, i.e., la liberación de los prisioneros de guerra, que además eran así colocados al amparo de la verdadera iglesia, de acuerdo a la Vida de Cesáreo, un documento póstumo, obra de los seguidores del obispo:

Que Dios no deje sin castigo a aquellos que han sometido injustificadamente a este inocente y santo hombre a un viaje tan largo. He sabido qué clase de hombre es cuando, al presentarse ante mí y saludarme, me he puesto a temblar. He visto el rostro de un ángel. He visto a un hombre apostólico. Es un error sospechar algún mal por parte de un hombre tan venerable $(\mathrm{l}, 36)$. 
Entre la correspondencia de Ennodio de Pavía, se ha conservado una carta dirigida a Cesáreo y fechada en 513, donde a manera de respuesta al informe que éste le había remitido sobre el encuentro en Ravena -informe que no se ha conservado- Ennodio responde con un cálido elogio por el éxito obtenido ante el rey. Los términos en que Ennodio presenta la entrevista en cuestión coinciden en parte con el relato de la Vida: también aquí se legitima el accionar de Cesáreo al colocar su figura en el marco de la tradición apostólica y se describe su mera presencia como inspiradora de pureza y deseos de emulación (IX 33, 4); pero además se ponderan sus cualidades oratorias y literarias, poniendo de manifiesto la patria y los intereses que ambos comparten: "¿De dónde procede esta prerrogativa de los habitantes del otro lado de los Alpes?" (IX 33,6).

Es que Ennodio encarna una de estas complejas figuras insertas en la encrucijada que representa para el Occidente romano el final del siglo V. De origen noble, cuenta dieciséis años cuando Teodorico asume el liderazgo en la península itálica, según él mismo refiere (Eucharisticon 20). Y efectivamente él, que había nacido en Arles, pero se había trasladado muy pronto a Pavía al quedarse huérfano, desarrolló su carrera eclesiástica a la par de numerosas misiones vinculadas con la corte de Teodorico (Delle Donne, 2001), un soberano bárbaro y arriano al que llegará a comparar con Alejandro, al que el ostrogodo supera por su fe cristiana:

La ignorancia, madre del error, dominó a aquel que desconocía la verdadera religión: a ti, desde el umbral de tu existencia, la doctrina de vida te instruyó en el culto al Dios supremo (...) Por tu fortaleza, tu solicitud, tu buena fortuna te comportas como príncipe, por tu mansedumbre como sacerdote (Panegírico 78-81).

Y de hecho, Ennodio tampoco deja escapar la ocasión de deslizar una serie de loas al soberano bajo cuya autoridad reside y al que los intelectuales de su círculo han sabido representar como paradigma de la mesura, la tolerancia respecto de la diversidad y el interés por la filosofía y las ciencias, aun cuando se tratara de un actor histórico portador de una doble alteridad, en su calidad de no romano/ no niceno: “¿Cuándo la púrpura del príncipe ha menospreciado los cilicios del monje o el palio de un obispo?" (IX 33, 2). Es que, en efecto, Ennodio es también autor de un extenso Panegírico de Teodorico, donde sus empresas bélicas aparecen justificadas en tanto dispuestas por una voluntad divina trascendente, especialmente su intervención contra Odoacro hasta el río Adige lucha a su lado (46)-, "¿Quién sino la voluntad divina propició que en un momento se extinguiera la desgracia del pueblo romano, acumulada durante un tiempo tan largo de perversidad? (52)" y se hace hincapié en su rol de protector de los valores de la romanitas, propiciando el cultivo de las letras, de las que presuntamente él mismo gozaba, al haber recibido una formación intelectual de fuste durante sus años como rehén en la corte constantinopolitana: "He ahí las riquezas de tu época: por entonces apenas tenían los foros oradores perfectos, hoy la Iglesia te envía un panegirista" (77). En sentido contrario, se alza el testimonio del Anónimo Valesiano, redactado hacia mediados del siglo VI, probablemente en Ravena, que califica al soberano como inlitteratus (Pizzani, 1998).

\section{Ennodio y la tradición lerinense - agustiniana}

Con todo, el trabajo de Ennodio más elocuente en relación al debate teológico que aquí nos interesa es su Eucharisticon, o Acción de gracias, de tono autobiográfico y que la crítica suele asociar al modelo de las Confesiones de Agustín. El texto plantea la cura providencial de una grave enfermedad como la circunstancia decisiva que lo impulsó a cultivar una conducta humilde, a partir de la comprensión de la omnipotencia divina 
y su necesaria intercesión para la materialización de las empresas humanas: “QQuién sería capaz de liberarme de este cuerpo de muerte? La gracia de Dios, concedida por la mediación de una enfermedad que me habría de curar" (7). Mientras que "todo aquello que se emprendía contra la enfermedad se revelaba como un fomento de la misma" y las artes de Hipócrates y Galeno ponían de manifiesto su vanidosa futilidad, los favores de san Víctor serán el único recurso efectivo (10-13).

Ennodio, cargado con múltiples faltas, destaca que esta intervención providencial no responde a una trayectoria vital meritoria, antes bien, se hace presente frente a la debilidad inválida que él mismo encarna en ese momento y exactamente esto es lo que convierte el auxilio divino en gratuito. Como Agustín, Ennodio recurre aquí a la autoridad de Pablo, el apóstol de la gracia: "aún no están las palabras en tu boca y ya acudo yo, dice el Señor". De esto se sigue que lo que solemos exhibir como méritos propios son verdaderamente y siempre hazañas de la divinidad. Recordemos que precisamente la práctica consciente de este aspecto constituye una de las notas que componen la encomiable personalidad de Teodorico, tal como se la presenta en el mencionado Panegírico: "Nunca atribuyes a tus esfuerzos lo que trae consigo un suceso favorable: sabes que de ti depende la planificación, pero que el poder de realizarlo está en manos de Dios" (80).

El panorama teológico que de este modo se delinea es convergente con las posiciones soteriológicas defendidas por Agustín y sus epígonos, entre los que debemos contar sin duda a Cesáreo de Arles. En efecto, el hecho de que Ennodio no pueda concebir su autobiografía sino como un gesto de agradecimiento hacia la divinidad marca una notable sintonía con aquellas posiciones, tal y como decantaran en los cánones de la ortodoxia instaurada por el segundo concilio de Orange. El foco de estas definiciones está puesto en la precedencia en todos los casos de la gracia divina respecto de la iniciativa humana, como réplica a la resistencia opuesta al obispo de Hipona por parte de los llamados semipelagianos.

Como su nombre lo indica -un nombre que no se acuñó sino en el siglo XVII, en el marco del enfrentamiento entre molinistas y jansenistas (Solignac, 1989) -, los representantes de tal postura son acusados de simpatizar parcialmente con las ideas de Pelagio, quien sostenía que la naturaleza se basta a sí misma para obtener su salvación, puesto que el pecado de Adán sólo había afectado a éste. Ciertamente, los miembros de este grupo revalorizarán el poder de la naturaleza, pero sin llegar a afirmar su exclusividad en el plano soteriológico, sino la de una sinergia necesaria para la consecución del bien en la esfera terrenal. En este escenario, por lo demás, la invocación y aceptación del don de la gracia por parte del libre albedrío serán fundamentales para reivindicar tanto la responsabilidad como los méritos de este último.

Entre los Opuscula de Ennodio, se encuentra también un texto perteneciente a la tradición hagiográfica, la Vida del monje Antonio, escrito a pedido del abad del monasterio de Lérins, Leoncio. Este enclave jugó un papel relevante en el desarrollo de los debates del siglo V, ya que allí residieron por entonces célebres defensores de la comentada sinergia, tales como Vicente de Lérins, escritor de un Commonitorium para la prevención de cualquier novedad o herejía, y Fausto de Riez, abad del monasterio entre los años 433 y 460, autor de un tratado conocido como De gratia. El cenobio debe haber mantenido contacto, además, con los que funcionaban en Marsella, San Víctor y San Salvador, que habían sido fundados por Juan Casiano, otro miembro de este frente polémico. Casiano contaba con la experiencia adquirida a través de la frecuentación de monjes en Palestina y Egipto, cuyas arduas prescripciones se había preocupado por adaptar a los ámbitos occidentales. Genadio de Marsella, por su parte, compuso un De virisillustribus, documento que contiene escasa información explícita acerca de sus opciones dogmáticas, pero que pondera especialmente a las personalidades hasta ahora mencionadas. 
Para la última década del siglo V, en cambio, encontramos a Cesáreo en Lérins, donde se retiró siguiendo su vocación ascética. En efecto, tal fue su compromiso con la vía emprendida que hacia el año 499 el abad le ordenó dirigirse a Arles para recuperar sus fuerzas. Es probable que tras el exilio impuesto a Fausto por el rey visigodo Eurico en 476 , el partido opositor a la gracia agustiniana se hubiera debilitado en alguna medida. En todo caso, durante el primer cuarto del siglo VI emergerá un detractor acérrimo del trabajo de Fausto, Fulgencio obispo de Ruspe, que en sus años dedicados a la vida monástica había elaborado un compendio de las ideas de Casiano. Asimismo, sabemos que en el año 500 viajó hasta Roma, en coincidencia con la visita del rey Teodorico. Por lo demás, fue víctima de las persecuciones vándalas en su Bizacena natal y de dos etapas de exilio en Cerdeña, impuestas por el rey Trasamundo. Durante la segunda, luego de 515, redactó mayormente sus tratados soteriológicos, entre ellos sus siete libros hoy perdidos Contra Faustum Reiensem. El tópico es recurrente en varias de sus cartas, como la 2 dirigida a Galla, hija del suegro de Boecio, aquel Símaco ejecutado por orden de Teodorico, y la 17, en respuesta a las inquietudes suscitadas por los trabajos de Fausto que unos monjes identificados como "escitas" le remiten a Cagliari. Se trataba probablemente de un grupo de godos del área de Dobruja, que se atreven incluso a acudir al papa Hormisdas en busca de una definición clara.

La perspectiva que asume Ennodio en esta Vida, naturalmente, difiere de la de su autobiografía. Y es que ya no se trata de un sujeto mundano y vanidoso, un pecador inválido, visiblemente necesitado de un auxilio que ni siquiera es capaz de solicitar por sí mismo. Se trata, por el contrario, de un varón santo. De este modo, el autor ya no busca agradecer lo inmerecido con su texto, tampoco cubrir de gloria el recuerdo de alguien que podría ciertamente prescindir de ella. En este caso, la letra configura un paradigma de santidad destinado al beneficio de todos sus lectores.

$\mathrm{Al}$ respecto, dice Ennodio algo de gran interés: "estos hombres, que ponen delante de nuestros ojos la gloria de su transformación" (3). Efectivamente, la transformación operada por los dones del Espíritu Santo (6) es necesaria, dada nuestra naturaleza corrupta. En el caso de Antonio, sin embargo, la gracia se manifiesta desde muy temprano, antes incluso de que él tenga uso de razón, cuando todavía es un lactante. Esto significa que el santo lo es por elección, ya que no ha tenido el tiempo ni las capacidades para proyectar y emprender la carrera de los méritos, en el momento en que su condición se ha manifestado. De hecho, su orfandad es entendida dentro de este marco providencial, precisamente "para que la blandura de sus padres no torciera lo establecido por los santos designios" (8). En esta misma senda, aparecen las figuras del ilustre tutor Severino, "quien al tiempo que le rodeaba de cariño, veía ya en ciernes, como si pertenecieran al pasado, las futuras virtudes del niño" (9), y de su tío, el obispo Constancio, que lo introdujo en la "milicia celestial".

"La mano de Cristo" (15 y ss.) guía, asimismo, a Antonio en su derrotero desde el Nórico hasta Lérins, mientras él mismo va cobrando conciencia de su verdadera vocación ascética, reconociendo la insignificancia de la belleza natural que lo rodea y la molestia que supone la fama entre los mortales. La isla se perfila como destino final del itinerario, en la medida en que representa un baluarte de la espiritualidad, a causa del prestigio de sus integrantes, así como también por el hecho de constituir una comunidad que ofrece apoyo al individuo: "Dirijámonos al ejército de los santos y busquemos con renovado ardor aquella cohorte de la isla de Lérins" (37).

En este contexto, Ennodio evidencia un aspecto controversial de la posición agustiniana, a saber, que la misma santidad requiere de la continuidad y confirmación de los dones gratuitos, puntualmente el que Agustín ha denominado "don de la perseverancia": "La perseverancia, con la que se persevera en el amor de Dios y de Cristo hasta el fin, esto es, hasta que se termina esta vida, en la cual únicamente hay peligro 
3. Afirma Agustín en la ya citada obra Sobre la predestinación de los santos VIII, 16: "Mas ¿por qué salva a uno con preferencia a otro? inescrutables son los juicios de Dios e ininvestigables sus caminos! Mejor nos será escuchar y decir aquí la palabra del Apóstol: ¡Oh hombre!, ¿quién eres tú para reconvenir a Dios?". de caer, es un don gratuito de Dios. Por ende, nadie sabe todavía si ha recibido ya tal don mientras vive en esta vida terrena, porque si cae antes de morir, se dice que no perseveró" (Sobre el don de la perseverancia I, 1).

Esta enunciación surgió como respuesta en las discusiones mantenidas con los integrantes de las comunidades monásticas que habían manifestado al obispo de Hipona su inquietud respecto de la eventual inutilidad de sus esfuerzos disciplinarios, dentro del horizonte de expectativas que definía la tesis de la predestinación. En este sentido, Ennodio hace a Antonio consciente de la dependencia de su situación en relación a la voluntad divina y, por ende, del carácter endeble y potencialmente reversible de aquélla: "No tienes la fe cierta acerca de tu perfección, mientras todavía estés encerrado en la fragilidad de la carne" (36). La conducta que corresponde al hombre no es la de una completa desidia, teniendo en cuenta la condición irrevocable de los designios divinos, ${ }^{3}$ sino la sumisión y la entrega confiada del propio ser al Padre y Creador de todo, ya que siempre tendremos la garantía de su justicia suprema:

¿Para qué recordar los instrumentos de perfección que utilizaba, aunque ya era perfecto; o los escalones por los que ascendió a las cumbres, él que, como era reconocido públicamente, había logrado ya la santidad? (22-24);

así a nuestro Antonio le acompañó por múltiples cambios de lugar la disciplina proveniente de Cristo (39).

De este modo, es posible en alguna medida enfrentar la pregunta inevitable: si su admirable virtud, tanto como la nobleza de su linaje, resulta en última instancia independiente de su libre albedrío, ¿para qué ofrecer el texto como guía de conducta y modelo a imitar?

\section{Tiempo y eternidad: las coordenadas de Boecio}

En 522, pocos años antes del final aciago, Boecio también dedicó un Panegírico al rey Teodorico, en ocasión de la distinción de sus dos hijos con el consulado. Boecio, que ocupó por su parte altos cargos en la administración del ostrogodo, parece haber sido especialmente apreciado por sus conocimientos técnicos, según se observa a partir de la documentación reunida por Casiodoro en sus Variae. ${ }^{4}$

4. De hecho, Teodorico le pide, siempre a través de Casiodoro, la disposición de dos relojes, uno solar y otro hidráulico, para el rey de los burgundios, Gundobado (I, 45), la elección de un citarista para enviar al soberano franco Clodoveo (II, 40), así como la inspección de un presunto fraude en el procedimiento de la acuñación de moneda $(\mathrm{l}, 10)$. V. el comentario de S. J. B. Barnish a su edición de 2006, Liverpool University Press.

5. Interesante, en todo caso, la posición ortodoxa de Boecio, un funcionario encumbrado del arriano Teodorico.
Además, a Boecio se le atribuye una serie de tratados teológicos, con el sostén del testimonio aportado por el Ordo generis Cassiodororum, publicado recién a fines del siglo XIX. Los textos, conocidos como Opuscula sacra, se ocupan de cuestiones dogmáticas polémicas para el momento, a saber, el monofisismo, el nestorianismo y el teopasquismo. ${ }^{5}$ Entre estos tratados encontramos un De fide catholica, un formato textual con unos contornos formales determinados y una función precisa: se trata, efectivamente, de compilaciones sobre diversas cuestiones dogmáticas, accesibles, portátiles, de consulta ágil. En esta línea, el trabajo de Boecio aborda en primera instancia artículos trinitarios y luego cristológicos, desacreditando a la vez de manera explícita a Arrio (30), Nestorio y Eutiques (210).

En el centro del texto (115 y ss.), sin embargo, aparece la impugnación nítida de la figura de Pelagio, junto con su negación de la dependencia humana respecto de la gracia divina. Boecio postula, entonces, la existencia de un grupo de sujetos elegidos por Dios para que obedezcan fielmente su voluntad, tras la merecida expulsión del Paraíso. De hecho, éste el único factor que puede explicar la presencia de hombres virtuoso, tales como Noé, Abraham, Moisés y la Virgen María, en la historia de una raza que, por sus propios 
medios, sólo se inclina hacia el vicio, funesta herencia del primer pecador. La expresión de la condición de desvalido de todo el género humano, así como la de la gratuidad de los dones divinos, que vuelve ineludible para los lectores el abismo insalvable entre eventuales méritos del hombre y el ejercicio magnánimo de la misericordia de Dios, posee ecos nítidamente agustinianos: "la diferencia entre lo que la gracia proporciona y lo que la naturaleza humana merece, una naturaleza simplemente sujeta al castigo; pero la gracia, que no se gana por méritos propios, puesto que no sería gracia lo que se concediera como compensación de tales méritos, confiere todo lo relativo a la salvación" (240).

Asimismo, en la célebre Consolación de la filosofía, escrito donde Boecio convierte esta disciplina en su principal interlocutor, al punto que ha hecho dudar a la crítica sobre sus preferencias religiosas personales, es posible observar la impronta de la soteriología agustiniana. Por supuesto, el neoplatonismo del texto resulta innegable (Chadwick, 1981), tanto como la influencia de esta tendencia filosófica sobre el pensamiento de Agustín. Sin embargo, la clave para la curación del alma sufriente de Boecio, esto es, la comprensión de que su situación no responde al azar, cruel en su ceguera, ni se encuentra bajo un yugo determinista, aunque verdaderamente "Dios obliga a todas las cosas a plegarse a un orden" (V, I, 8-10), se puede remitir rápidamente al libro XII de las Confesiones, amén del ya aludido Sobre la predestinación de los santos. La misma radica en la distinción de las dos coordenadas ontológicas paralelas en que deben situarse el Creador y el conjunto de su creación:

la verdadera eternidad del Creador, que su sustancia no varía de ningún modo con los tiempos, ni su voluntad es extraña a su sustancia, razón por la que no quiere ahora esto y luego aquello, sino que todas las cosas que quiere las quiere de una vez, siempre, simultáneamente [...] porque semejante voluntad sería mudable y todo lo que es mudable no es eterno y nuestro Dios es eterno [...] asimismo, la expectación de las cosas se transforma en visión cuando llegan, así como la visión se transforma en memoria cuando han pasado [...] yo agrupo estas dos verdades y las junto y hallo que mi Dios, Dios eterno, no creó con nueva voluntad el mundo, ni su ciencia puede parecer algo transitorio (Conf. XII, 25).

Así, mientras la vida de las criaturas se desenvuelve en el tiempo y, de hecho, las dimensiones del pasado, el presente y el futuro le son constitutivas, el Creador quiere y actúa desde la eternidad, se mantiene ajeno al transcurrir temporal, contrario a su ser perfectamente inconmovible. Esta diferencia ontológica permite explicar que Dios tenga ante sí, sinópticamente el total de los acontecimientos del mundo y posea necesariamente una presciencia de los mismos:

Las cosas que son, que han sido y que serán,

Las ve con una sola mirada de su mente $(\mathrm{V}, \mathrm{Il}, 10)$.

Esta presciencia no supone, sin embargo, la injerencia constante de la divinidad en el plano de los proyectos y las acciones del hombre, anulando efectivamente su libertad. Por el contrario, como criaturas racionales los hombres conservan su capacidad de decidir, aunque sus poderes efectivos sean relativamente inferiores: "aquellos que poseen por sí mismos razón, poseen también la libertad de querer y no querer; pero te advierto que esta libertad no es igual en todos" (V, I, 6-7). En efecto, si en el caso de la divinidad, agudeza de juicio e integridad de la voluntad van siempre a la par, los hombres incrementan su libertad con la cercanía respecto de las realidades inteligibles y la disminuyen con el apego hacia lo terrenal. Así, aunque el universo se encuentre regulado por la ley divina, el hombre vive en un ámbito que incluye regiones contingentes, donde conserva pues un modesto margen de acción, por lo que la providencia puede pensarse realmente como una garantía para la fragilidad humana, ya que no anula la libertad ni la responsabilidad. 


\section{La biblioteca de Casiodoro}

Casiodoro se retiró de la actividad política en 537, dejando el cargo de prefecto del pretorio que Atalarico le había conferido en 533. Anteriormente, durante el reinado de Teodorico, se había desempeñado como consiliarius, cuestor, cónsul ordinario y magister officiorum, en reemplazo de su amigo y pariente, Boecio. Las Variae constituyen un testimonio importante de esta carrera, ya que reúnen la documentación emitida por entonces bajo su propio nombre o el del soberano, compilada luego del retiro, presumiblemente tras una cuidadosa labor de selección que ha excluido, por ejemplo, cualquier referencia al malhadado proceso contra Boecio.

Las Institutiones, en cambio, son elocuentes respecto del signo bajo el que se desarrolla esta segunda etapa de su vida. De hecho, Casiodoro se aboca al establecimiento del monasterio de Vivarium, de cuyo funcionamiento se conocen pocos detalles, i.e., si estaba en vigencia la regla de San Benito o si él mismo había asumido las funciones de abad (Di Berardino, 2000). Sin embargo, gracias a la mencionada fuente, sabemos que contaba con una biblioteca considerable y que la lectura, atenta y reflexiva, era una actividad central para la institución.

Según las declaraciones del Prefacio, el texto se propone compensar la falta de instrucción en materia de las santas Escrituras, frente al cultivo más amplio de las disciplinas seculares, máxime en tiempos de gran inestabilidad política, debido a la guerra greco-gótica. Con este propósito, Casiodoro aporta una guía ordenada de las lecturas sugeridas, preferentemente en latín, dado que "se recibe más dulcemente lo que se narra en lengua paterna" (4), aunque se deja la puerta abierta para quien tenga la iniciativa de encarar el estudio de la exégesis griega, poniendo de manifiesto a la vez el contenido de la biblioteca presente en Vivarium.

Así, la primera parte del trabajo consigna la serie de autoridades patrísticas que conviene consultar para el enfoque de los distintos libros que componen las Escrituras, panorama en que se destacan las figuras de Jerónimo, Ambrosio, así como de los griegos Orígenes, Eusebio, pero donde también sobresale indiscutiblemente la extensa producción de Agustín:

Si alguien desea depurar sus propias palabras con un examen escrupuloso y no delinquir por incauta temeridad, recorra con atenta lectura los dos libros de las Retractaciones de san Agustín, ya que al imitarlos se adornará y conocerá cuánta abundancia de sabiduría la indulgencia divina otorgó al beatísimo Padre; de modo que a él, a quien nadie podía criticar, le pareció oportuno corregirse con una revisión muy cuidada (XVI, 4).

El texto registra, por lo demás, algunas indicaciones relativas a la utilidad de las disciplinas seculares, la historia, la cosmografía, la medicina, la retórica, la ortografía, siempre aplicadas al mejor entendimiento de las letras sagradas. De hecho, la erudición nunca debe convertirse en motivo de pedantería: "no violéis los idiotismos de las divinas Escrituras por presunción alguna para que, deseando adaptar lo que se ha dicho de modo que pueda ser entendido por todos, no se disipe la pureza de las palabras celestes" $(\mathrm{XV}, 2)$.

Dentro del conjunto se precia, asimismo, el encomio de los textos e instancias conciliares consagrados a exterminar las herejías. Casiodoro es enfático a este respecto: "Rechácense totalmente las opiniones de aquellos a quienes condenó la Iglesia providente y si alguno tal, evítese con cautísimo escrúpulo" (XXII). Además de ponderar especialmente el material de Agustín en este frente (XXII), él mismo se ha entregado a depurar la transmisión corrupta, "por los venenos de la herejía pelagiana" (VIII, 1), 
de los textos paulinos. Se trata de las Expositiones XIII epistularum Pauli, compuestas en Roma entre 406 y 409, ${ }^{6}$ que Casiodoro conoce bajo el nombre del papa Gelasio.

En el ámbito de los debates soteriológicos, en efecto, Casiodoro toma también posición en relación a la aludida resistencia gala que, de por cierto, había sido ya condenada en el concilio de Orange de 529. De este modo, aunque recomienda "leed atentamente y oíd con gusto al presbítero Casiano, que escribió la regla de los fieles monjes", no deja de anotar y suscribir el llamado de atención al respecto por parte de Próspero de Aquitania, un epígono de Agustín: "San Próspero, sin embargo, le censuró justamente su concepción del libre arbitrio, por lo que aconsejamos que os mováis con cautela al leer a quien se propasa en tales asuntos" (XXIX, 2).

Cabe poner en relación el hecho de que Casiodoro adjudique aquí el epíteto ‘santo' a Próspero con la atribución del mismo epíteto justamente a Casiano en el De viris illustribus de Genadio de Marsella: "[Euquerio de Lyon] recogió en un volumen algunas de las obras más extensas del santo Casiano, revisándolas y condensándolas, junto con otras de gran utilidad tanto para las labores eclesiásticas como para las monásticas" (64). Así, Genadio se encolumna abiertamente detrás de Casiano en el tratamiento de las cuestiones ligadas a la gracia y el libre albedrío: "He leído, además, un texto suyo donde ataca la obra de Casiano, sin hacer mención del nombre de éste, obra que la iglesia ha considerado provechosa y que él juzga nociva. Casiano y Próspero sostienen posiciones encontradas respecto de la gracia y el libre albedrío" (85).

Digamos, finalmente, que Casiodoro conoce y utiliza este escrito de Genadio, que menciona entre los historiadores cristianos. Más aún, es quizás responsable por la secular transmisión de este catálogo asociado constantemente al homónimo de Jerónimo en los manuscritos, debido a una operación editorial con miras pragmáticas, que declara haber llevado a cabo en la disposición de su famosa biblioteca:

lee el libro Sobre los hombres ilustres de san Jerónimo, en el que trató brevemente sobre diversos Padres y sus opúsculos, a quienes honró y de los que se ocupó brevemente. Después, el otro libro de Genadio de Marsella, quien igualmente indicó con total certeza lo mismo, acerca de los escritores de la ley divina a los que había estudiado detenidamente. Dejé estos dos libros reunidos en un volumen, para que no se retrase el conocimiento de las cosas por encontrarse desperdigadas en varios tomos (XVII, 2).

\section{A modo de conclusión}

El siglo VI se abre con la consagración de Cesáreo al episcopado de Arles en 502, principal impulsor de la reivindicación de la autoridad agustiniana en el campo de la soteriología en la reunión conciliar de Orange de 529. Las tesis proscriptas en esta instancia, i.e., la iniciativa de la libre elección humana en el arduo camino de la salvación, la negación de la predestinación y, en consecuencia, el alcance universal del llamado de Cristo para todos los pecadores, habían florecido durante el siglo anterior hasta hacer frente al profundo intelecto teológico del africano Agustín.

La muerte de Fausto, obispo de Riez, hacia fines del siglo V debe haber señalado el inicio del declive de las mencionadas ideas en las instituciones monásticas galas, donde habían prosperado especialmente bajo sus auspicios y el de fecundos escritores, Juan Casiano, Vicente de Lérins, Genadio de Marsella. De hecho, los actores históricos que encontramos vinculados a Lérins durante los años siguientes, como
6. V. el estudio introductorio de Sara Matteoli a la traducción de dos comentarios pelagianos: Pelagio, Commento all'Epistola ai Romani, Commento alle Epistole ai Corinzi, Roma, Città Nuova, 2012. 
7. Cf. el estudio introductorio de Antonino Isola a su traducción de las cartas supérstites: Fulgenzio di Ruspe, Le Lettere, Roma, Città Nuova, 1999.

8. “E quibus legimus de gratia Dei et libero arbitrio libros responsionum septem, in quibus Fausto Galliae Regiensi urbis episcopo, pelagianae pravitati consentienti, respondens obnititur eius profundam destruere calliditatem". el mismo Cesáreo o Ennodio, se inclinan de manera más o menos explícita hacia la interpretación agustiniana del destino humano.

Ennodio, por su parte, se halla en la península itálica, dentro de la órbita de influencia de las políticas culturales de Teodorico, favorable al cultivo de las letras latinas y tolerante con el culto cristiano. Junto a Ennodio, destacan en este círculo Boecio y Casiodoro, quienes al amparo del soberano ostrogodo generan un corpus de documentos tendiente a conservar elementos de la civilización romana ya cristianizada, donde Agustín constituye una influencia visible. Por lo demás, sobre mediados del siglo VI hace su aparición la Regla de san Benito, que pronto eclipsará el enorme ascendiente directo de Casiano en la espiritualidad monástica occidental. Así, en territorio galo es mencionada por primera vez en 625 y es posible que influyera incluso sobre la actividad de Columbano, a partir del sentido elogio que le diera Gregorio Magno en sus Dialogi de vita et miraculis patrum italicorum. Finalmente, los carolingios la impondrán como texto de adopción general, en el marco de una política de homogeneización de los monasterios (De Vogüé, 1999).

Otro foco de actividad literaria a favor de Agustín durante el siglo VI se sitúa en la conflictiva África vándala, desde donde el agustiniano Fulgencio de Ruspe será expulsado. En su exilio en Cagliari, emprende una enérgica defensa de la soteriología del Doctor Gratiae, que continuará tras la vuelta definitiva a Ruspe, luego de la muerte de Trasamundo en 523. Su epistolario nos permite ver que por entonces emerge también un núcleo oriental de disidentes en relación a las ideas transmitidas por la literatura provenzal del siglo V, especialmente la impugnación de la predestinación. Entre estos disidentes, algunos identificados como 'escitas' son los que escriben a Fulgencio y se trasladan hasta Roma para solicitar una respuesta contundente por parte del papa Hormisdas que, en cambio, los acusó de agitar viejas cuestiones. ${ }^{7}$ Para el pontífice, ciertamente, la discusión estaba ya definitivamente clausurada a partir de las palabras que Agustín había dirigido a Próspero e Hilario entre los años 428 y 429, el momento más virulento de la resistencia en Marsella, según escribe en una epístola fechada en 523, todavía seis años antes de la sanción oficial de Orange. La misiva en cuestión era para Posesor, un obispo africano que hacia el año 520 informa a Hormisdas acerca de la animosidad que suscitan los libros de Fausto en Constantinopla. Desde la Sevilla visigoda, por su parte, Isidoro se hace eco elogiosamente del comentado trabajo de Fulgencio, ${ }^{8}$ en su De viris illustribus (14), redactado entre los años 615-618 (Codoñer Merino, 1964), cerrando un siglo donde predominan las voces más o menos abiertamente favorables a Agustín. 


\section{Bibliografía}

\section{Fuentes}

»Agustín, Confesiones, Madrid, BAC, 1950.

" Agustín, Tratados sobre la Gracia, Madrid, BAC, 1952.

"Boecio, La consolación de la Filosofía, Madrid, Akal, 2009.

"Boethius, The Theological Tractates and the Consolation of Philosophy, Loeb 74, Harvard University Press, 1968.

》Caesarius of Arles, Life, Testament, Letters. Liverpool University Press, 1994.

"Casiodoro, Iniciación a las sagradas Escrituras. Madrid, Ciudad Nueva, 1998.

"Cassiodorus, Variae, Liverpool University Press, 2006.

》Enodio de Pavía, Opúsculos y Declamaciones, Madrid, Gredos, 2007.

»Enodio de Pavía, Poemas. Epístolas, Madrid, Gredos, 2012.

" Genadio de Marsella, De viris illustribus, TU, Leipzig, 1896.

» Fausto di Riez, La Grazia, Roma, Città Nuova, 2004.

" Fulgenzio di Ruspe, Le Lettere, Roma, Città Nuova, 1999.

»Isidoro de Sevilla, De viris illustribus, estudio y edición crítica a cargo de C. Codoñer Merino, Salamanca, CSIC, 1964.

"Jean Cassien, Conférences, SC 42 bis, Paris, (1955) 2008.

»Pelagio, Commento all'Epistola ai Romani, Commento alle Epistole ai Corinzi, Roma, Città Nuova, 2012.

»Vicenzo di Lérins, Commonitorio, Milano, Paoline, 2008.

\section{Comentarios, artículos, ensayos}

" Alfonsi, L. (1943). "Problemi filosofici della Consolatio boeziana”, en: Rivista di Filosofia $\mathrm{Neo}$ - scolastica, vol. $35 \mathrm{~N}^{\circ} 5 / 6$, pp. $323-328$.

" Chadwick, H. (1981). Boethius. The Consolations of Music, Logic, Theology and Philosophy, Oxford University Press.

"Delle Donne, F. (2001). "Il ruolo storico e politico di Ennodio", en: Gasti, F. Atti della prima Giornata Ennodiana, Pavia, 29-30 marzo 200o, Pisa, ETS, 2001, pp. 7-19.

»De Vogüé, A. (1999). San Benedetto. Uomo di Dio, Milano, San Paolo.

"Di Berardino, A. (2000). Patrología IV, Madrid, BAC.

" Gioanni, S. (2007). "Une figure suspecte de la sainteté lérinienne: saint Antoine d'après la Vita Antoni d' Ennode de Pavie”, en: Recherches augustiniennes et patristiques 35, pp. 133-187. 
"Klingshirn, W. (1994). Caesarius of Arles. The making of a Christian Community in Late Antique Gaul. Cambridge University Press.

»Pizzani, U. (1998). "Le lettere di Teodorico a Boezio e la mediazione culturale di Cassiodoro", en: Rivista di Studi sulla Tarda Antichità 4, Rubbettino, pp. 141-161.

» Solignac, A. (1989). “Semipélagiens”, en Dictionnaire de spiritualité ascétique et mystique, XIV. Paris, Beauchesne.

» Trapé, A. (1990). S. Agostino: Introduzione alla dottrina della grazia, vol. II, Roma, Città Nuova. 